\title{
Effects of CoQ10 supplementation and swimming training on exhaustive exercise-induced oxidative stress in rat heart
}

\author{
Okudan $\mathrm{N}^{1}$, Revan $\mathrm{S}^{2}$, Balci SS${ }^{3}$, Belviranli $\mathrm{M}^{1}$, Pepe $\mathrm{H}^{2}$, Gökbel $\mathrm{H}^{1}$ \\ Department of Physiology, Meram Faculty of Medicine, Selçuk University, Meram, Konya, Turkey. \\ nokudan@selcuk.edu.tr
}

\begin{abstract}
This study examined the combined effects of swimming training and coenzyme $Q_{10}\left(C_{0} Q_{10}\right)$ supplementation on exhaustive exercise-induced oxidative stress in rat heart. The study was carried out with 4-monthold young adult male Wistar rats. Sixty four rats were divided mainly into two groups: trained and control. Each group was further divided into four subgroups: rest, exhausted, rest with $\mathrm{CoQ}_{10}$, exhausted with $\mathrm{CoQ}_{10}$. The training program consisted of swimming one hour each day, five days a week, for six weeks. At the end of sixth week, rats in exhausted exercise group were forced to swim until exhaustion and then they were immediately sacrificed, while rats in rest group were sacrificed at rest. Training alone or in combination with $\mathrm{CoQ}_{10}$ supplementation reduced to increasing MDA levels due to exhaustive exercise in rat heart $(p<0.05)$. The trained-rest with $\mathrm{CoQ}_{10}$ group showed lower 8-OHdG levels than the control-rest with $\mathrm{CoQ}_{10}$ group. Exhaustive exercise effect was significant on SOD activity. Exhaustive exercise increased GSH levels in control groups while decreased GSH levels in training groups $(p<0.05)$. In conclusion, the results suggest that $\mathrm{Co}_{10}$ supplementation combined with training may inhibit lipid peroxidation and DNA damage in the heart tissue. Also, it can be said that SOD activity and GSH levels were not influenced by $\mathrm{CoQ}_{10}$ supplementation (Fig. 4, Tab. 1, Ref. 69). Full Text in PDF www.elis.sk.

Key words: $\mathrm{CoQ}_{10}$, swimming training, oxidative stress.
\end{abstract}

Regular physical activity is associated with enhanced health and reduced risk of all-cause mortality such as cardiovascular disease, hypertension, type 2 diabetes, obesity, osteoporosis, sarcopenia, cognitive disorders, and some forms of cancer (1). However, it is well accepted that acute physical exercise increases oxygen uptake and free-radical production, and consequently could induce oxidative stress and oxidative damage associated with the type, frequency, intensity and duration of exercise $(2,3)$. Acute strenuous exercise may pose a risk to the heart by generating oxidative stress, while chronic exercise may beneficially influence cardiac antioxidant defenses and support overall cardiac function (4).

Cells continuously produce free radicals and reactive oxygen species (ROS) as part of metabolic processes $(5,6)$. ROS play a key role in modulating changes in gene expression and cell function, and act through the key signalling and response systems of cells (7). Overproduction of ROS, most frequently either by excessive stimulation of $\mathrm{NAD}(\mathrm{P}) \mathrm{H}$ by cytokines, or by the mitochondrial

${ }^{1}$ Department of Physiology, Meram Faculty of Medicine, Selçuk University, Meram, Konya, Turkey, ${ }^{2}$ Department of Physical Education and Sports, School of Physical Education and Sports, Selçuk University, Seçuklu, Konya, Turkey, and ${ }^{3}$ Department of Trainer Education, School of Physical Education and Sports, Selçuk University, Selçuklu, Konya, Turkey

Address for correspondence: N. Okudan, PhD, Department of Physiology, Meram Faculty of Medicine, Selçuk University, Meram, Konya, Turkey. Phone: +90.332.2233213, Fax: +90.332.2411608

Acknowledgements: This study was supported by Selçuk University, Scientific Research Projects (S.U.-BAP, Konya, Turkey; Project No. 6401032). This research has been presented in part at the 3th Symposium of Exercise Physiology on May 13-14, 2011, in Adana, Turkey. electron transport chain and xanthine oxidase result in oxidative stress. Oxidative stress is a deleterious process that can be an important mediator of damage to cell structures and consequently various disease states and ageing (8). The harmful effect of oxidative stress is counteracted by the antioxidant action of both antioxidant enzymes and non-enzymatic antioxidants (9). Antioxidant enzymes include superoxide dismutase, glutathione peroxidase and catalase. Non-enzymatic antioxidants include vitamins $\mathrm{E}$ and $\mathrm{C}, \beta$-carotene, glutathione and coenzyme $\mathrm{Q}_{10}$ (ubiquinone, $\mathrm{CoQ}_{10}$ ) (10).

$\mathrm{CoQ}_{10}$ is a lipid-soluble component of virtually all cell membranes and has multiple metabolic functions (11). The most wellknown function of $\mathrm{CoQ}_{10}$ is that it is an essential carrier for the electron transfer in the mitochondrial respiratory chain for ATP generation $(12,13)$. Another important function of $\mathrm{CoQ}_{10}$ is as a lipophilic antioxidant (14-16). In addition, $\mathrm{CoQ}_{10}$ has an important role in cell signalling and gene expression $(17,18)$. Supplementation of $\mathrm{CoQ}_{10 \text { has }}$ also been indicated to increase aerobic or anaerobic capacity $(19,20)$ and might prevent unfavorable conditions as a result of physical fatigue (21). Besides, it has been used for the treatment of cardiovascular diseases such as congestive heart failure (22) and atherosclerosis (23), cancer (24), diabetes (25), hypertension (26) and neurodegenerative diseases $(27,28)$.

However, little is known about the effects of $\mathrm{CoQ}_{10}$ and chronic exercise training on acute exhaustive exercise-induced oxidative stress. Thus, we aimed to investigate the effect of regular swimming exercise and $\mathrm{CoQ}_{10}$ supplementation on the levels of MDA, a marker of lipid peroxidation; 8-OHdG levels, a marker of DNA damage; the levels of GSH, an endogenous antioxidant and SOD activity, an antioxidant enzyme after acute exhaustive exercise. 


\section{Materials and methods}

Animals

Sixty four young adult male Wistar rats (4 month old) were used in the study and were cared for according to the guiding Principles for the Care and Use of Animals based upon the Helsinki Declaration, 1964. All procedures were approved by the Selcuk University Experimental Medicine Research and Application Center Experimental Animal Ethics Committee. During the study, all rats were housed in polycarbonate cages, four rats per cage, in a temperature-controlled room $\left(23^{\circ} \mathrm{C}\right)$ with a 12 :12-h light-dark cycle and were given standard rat chow and water ad libitum.

\section{Exercise procedures}

The animals were divided mainly into two groups: trained (T) and control (C). Each group was further divided into four subgroups: trained-rest (TR, $n=8)$, trained-exhausted (TE, $n=8$ ), trained-rest with $\mathrm{CoQ}_{10}\left(\mathrm{TR}+\mathrm{CoQ}_{10}, \mathrm{n}=8\right)$, trained-exhausted with $\mathrm{CoQ}_{10}\left(\mathrm{TE}+\mathrm{CoQ}_{10}, \mathrm{n}=8\right)$, control-rest $(\mathrm{CR}, \mathrm{n}=8)$, control-exhausted $(\mathrm{CE}, \mathrm{n}=8)$, control-rest with $\mathrm{CoQ}_{10}\left(\mathrm{CR}+\mathrm{CoQ}_{10}, \mathrm{n}=8\right)$ and controlexhausted with $\mathrm{CoQ}_{10}\left(\mathrm{CE}+\mathrm{CoQ}_{10}, \mathrm{n}=8\right)$. Swimming protocol was adapted from the protocol developed by Kwon et al. (29). The exercise groups were adapted to the swimming training for five days (20 min/day). After this period of familirization to exercise, the rats in the trained groups underwent an exercise protocol of one hour continuous swimming per day, five days per week for six weeks, whereas the control groups did not exercise. Swimming was performed in a container (length $100 \mathrm{~cm}$, width $50 \mathrm{~cm}$, depth $50 \mathrm{~cm}$ ) containing water maintained at $32-34^{\circ} \mathrm{C}$ and eight rats were allowed to swim together. $\mathrm{CoQ}_{10}$ (Sigma-Aldrich; Cat. No. C-9538, St. Louis, MO, USA) was intraperitoneally applied daily with the ratio of $10 \mathrm{mg} / \mathrm{kg} /$ body weight in the $\mathrm{CoQ}_{10}$ treated rats for six weeks. At the end of six weeks training period, the acute bout of exhaustive exercise was performed 48 hours after the last exercise session. In exhaustive swimming groups (TE, $\mathrm{TE}+\mathrm{CoQ}_{10}, \mathrm{CE}, \mathrm{CE}+\mathrm{CoQ}_{10}$ ), the rats were forced to swim until exhaustion and then were sacrificed by heart puncture under ether anesthesia. Exhaustion was determined by the inability of the rat to remain at the surface of water more than 10 seconds (30). The other rest groups were sacrificed 48 hours after the last exercise session and/or last $\mathrm{CoQ}_{10}$ administration.

\section{Tissue preparation and biochemical analysis}

Heart tissues were homogenized in 10 volumes of ice-cold Tris$\mathrm{HCl}$ buffer (50 mmol/L, pH 7.4) using a homogenizer (Wise Mix HG-15; Daihan Scientific, Seoul, Korea) after cutting the organs into small pieces. Levels of 8-OHdG and GSH and SOD activities were determined in this homogenate. Some of the homogenate was centrifuged and its supernatant was separated. The supernatant solution was extracted with an equal volume of an ethanol/chloroform mixture (5/3, volume per volume $[\mathrm{v} / \mathrm{v}])$. After centrifugation at $5000 \mathrm{~g}$ for $30 \mathrm{~min}$, the upper layer (the ethanol phase) was used in the protein assays. Lipid peroxidation was estimated using a commercially available kit according to the manufacturer's recommendations and MDA as a standard (TBARS kit; Cat. \#10009055, Cayman Chemical Co., Ann Arbor, MI, USA). Absorbance was measured at $530 \mathrm{~nm}$. GSH was determined by a Cayman's GSH assay kit (Cat. \#703002, Cayman Chemical Co., Ann Arbor, MI, USA) using an enzymatic recycling method. Briefly, GSH reacts with 5,5-dithio-bis-2- nitrobenzoic acid (Ellman's reagent) using the sulfhydryl group and produces a yellow-colored 5-thio-2-nitrobenzoic acid (TNB). The mixed disulfide, GSTNB (between GSH and TNB), which is concomitantly produced, is reduced by glutathione reductase to recycle the GSH and produce more TNB. The rate of TNB production is directly proportional to this recycling reaction, which in turn is directly proportional to the concentration

Tab. 1. The effects of swimming training, coenzyme $Q_{10}$ supplementation and acute exhaustive exercise on plasma levels of MDA, 8-OH-dG, GSH and SOD activity.

\begin{tabular}{|c|c|c|c|c|c|c|c|c|c|c|c|c|}
\hline & \multirow[t]{2}{*}{ Groups } & \multicolumn{2}{|c|}{ Control } & \multicolumn{2}{|c|}{ Training } & \multirow[t]{2}{*}{$\mathrm{CoQ}_{10}$} & \multirow[t]{2}{*}{ ST } & \multirow[t]{2}{*}{$\mathrm{EE}$} & \multirow[t]{2}{*}{$\mathrm{CoQ}_{10} * \mathrm{ST}$} & \multirow[t]{2}{*}{$\mathrm{CoQ}_{10} * \mathrm{EE}$} & \multirow[t]{2}{*}{ ST*EE } & \multirow[t]{2}{*}{$\mathrm{CoQ}_{10} * \mathrm{ST} * \mathrm{EE}$} \\
\hline & & Mean & \pm SEM & Mean & \pm SEM & & & & & & & \\
\hline MDA & $\mathrm{R}$ & 0.65 & \pm 0.07 & 1.05 & \pm 0.05 & & & & & & & \\
\hline \multirow[t]{3}{*}{ ( $\mu \mathrm{M} / \mathrm{g}$ tissue) } & E & 1.02 & \pm 0.07 & 0.61 & \pm 0.03 & 0.71 & 0.25 & 2.68 & 0.10 & 0.39 & $23.10^{¥}$ & $19.29^{¥}$ \\
\hline & $\mathrm{R}+\mathrm{CoQ}_{10}$ & 0.94 & \pm 0.05 & 0.95 & \pm 0.02 & & & & & & & \\
\hline & $\mathrm{E}+\mathrm{CoQ}_{10}$ & 0.84 & \pm 0.04 & 0.89 & \pm 0.10 & & & & & & & \\
\hline \multirow{4}{*}{$\begin{array}{c}\text { 8-OH-dG } \\
\text { (pg/g tissue) }\end{array}$} & $\mathrm{CR}$ & 58.20 & \pm 4.02 & 69.80 & \pm 1.48 & & & & & & & \\
\hline & $\mathrm{CE}$ & 69.09 & \pm 2.60 & 66.65 & \pm 2.06 & 2.85 & 0.00 & $4.38^{¥}$ & $4.63^{¥}$ & 0.05 & 1.59 & 3.93 \\
\hline & $\mathrm{CR}+\mathrm{CoQ}_{10}$ & 62.92 & \pm 3.25 & 56.85 & \pm 2.84 & & & & & & & \\
\hline & $\mathrm{CE}+\mathrm{CoQ}_{10}$ & 66.35 & \pm 3.26 & 63.37 & \pm 1.02 & & & & & & & \\
\hline \multirow{4}{*}{$\begin{array}{c}\text { GSH } \\
(\mu \mathrm{M} / \mathrm{g} \text { tissue })\end{array}$} & $\mathrm{CR}$ & 1.87 & \pm 0.17 & 2.19 & \pm 0.09 & & & & & & & \\
\hline & $\mathrm{CE}$ & 2.34 & \pm 0.07 & 1.94 & \pm 0.11 & 0.01 & 0.01 & 0.01 & 0.00 & 0.05 & $6.66^{\ddagger}$ & 3.64 \\
\hline & $\mathrm{CR}+\mathrm{CoQ}_{10}$ & 2.08 & \pm 0.12 & 2.09 & \pm 0.08 & & & & & & & \\
\hline & $\mathrm{CE}+\mathrm{CoQ}_{10}$ & 2.09 & \pm 0.05 & 2.02 & \pm 0.10 & & & & & & & \\
\hline \multirow{3}{*}{$\begin{array}{c}\text { SOD } \\
(\mathrm{U} / \mathrm{mg} \text { protein) }\end{array}$} & $\mathrm{CR}$ & 0.26 & \pm 0.06 & 0.22 & \pm 0.08 & & & & & & & \\
\hline & $\mathrm{CE}$ & 0.15 & \pm 0.04 & 0.36 & \pm 0.11 & 0.25 & 0.13 & $5.71^{¥}$ & 3.47 & 1.27 & 1.99 & 3.82 \\
\hline & $\mathrm{CE}+\mathrm{CoQ}_{10}$ & 0.43 & \pm 0.09 & 0.30 & \pm 0.05 & & & & & & & \\
\hline
\end{tabular}

$\mathrm{CoQ}_{10}$ main effect of coenzyme $\mathrm{Q}_{10}$, ST; main effect of swimming training, EE; main effect of exhaustive exercise, CoQ ${ }_{10}{ }^{*} \mathrm{ST}$; interaction effect between coenzyme $\mathrm{Q}_{10}$ and swimming training, $\mathrm{CoQ}_{10}{ }^{*} \mathrm{EE}$; interaction effect between coenzyme $\mathrm{Q}_{10}$ and exhaustive exercise, ST*EE; interaction effect between swimming training and exhaustive exercise, $\mathrm{CoQ}_{10} * \mathrm{ST} * \mathrm{EE}$; interaction effect among coenzyme $\mathrm{Q}_{10}$, swimming training and exhaustive exercise. $\mathrm{R}$; rest group, $\mathrm{E}$; exhausted group, $\mathrm{R}+\mathrm{CoQ}$; ; rest with coenzyme $\mathrm{Q}_{10}$ group, $\mathrm{E}+\mathrm{CoQ}_{10}$; exhausted with coenzyme $\mathrm{Q}_{10}$ group. ${ }^{¥} \mathrm{p}<0.05$ significant main or interaction effect (three-way ANOVA). 


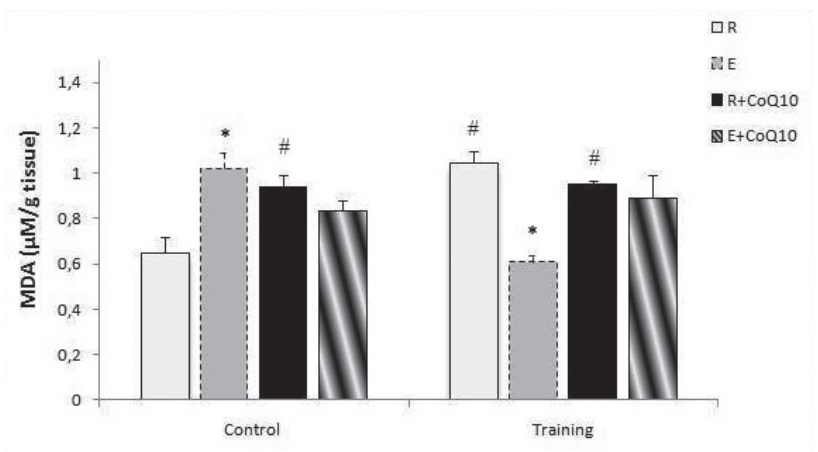

Fig. 1. The effects of swimming training, $\operatorname{CoQ}_{10}$ supplementation and acute exhaustive exercise on malondialdehyde (MDA) in the rat heart. The data are presented as means \pm SEM. There was a significant interaction effect between training and exhaustive exercise on MDA level $(F=23.10, p<0.05)$. A significant interaction effect among the training, $\mathrm{CoQ}_{10}$ supplementation and acute exhaustive exercise was observed on the MDA levels in the rat heart $(F=19.29, p<0.05) . R=$ Rest group, $\mathrm{E}=$ Exhausted group, $\mathrm{R}+\mathrm{CoQ}_{10}=$ Rest group with $\mathrm{CoQ}_{10}$ supplement, $\mathrm{E}+\mathrm{CoQ}_{10}=$ Exhausted group with $\mathrm{CoQ}_{10}$ supplement. " $p$ $<0.05$ significantly different from the control or training rest group. ${ }^{*}$ $p<0.05$ significantly different from the control rest group.

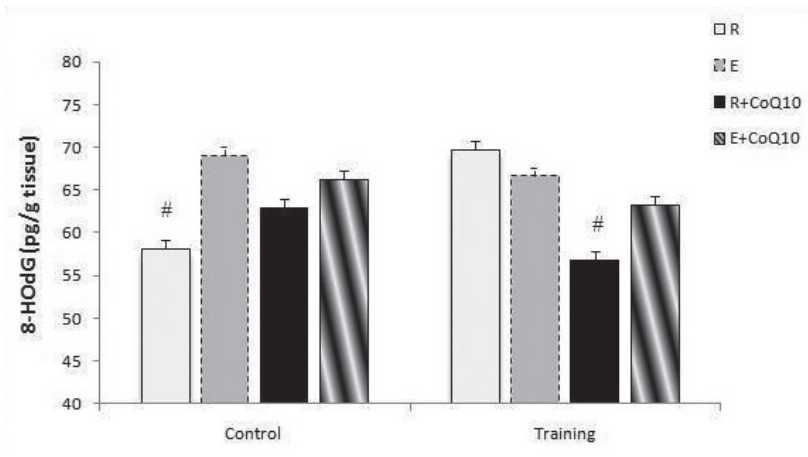

Fig. 2. The effects of swimming training, $\mathrm{CoQ}_{10}$ supplementation and acute exhaustive exercise on 8-hydroxy-2-deoxy Guanosine (8-OHdG) in the rat heart. The data are presented as means \pm SEM. The 8-OHdG level in heart tissue was significantly affected by exhaustive exercise $(F=4.38, p<0.05)$. There was a significant interaction effect of $\mathrm{CoQ}_{10}$ supplementation and training on the 8-OHdG level in heart tissue $(\mathrm{F}$ $=4.63, \mathrm{p}<0.05) . \mathrm{R}=$ Rest group, $\mathrm{E}=$ Exhausted group, $\mathrm{R}+\mathrm{Co}_{10}=$ Rest group with $\mathrm{CoQ}_{10}$ supplement, $\mathrm{E}+\mathrm{CoQ}_{10}=$ Exhausted group with $\mathrm{CoQ}_{10}$ supplement. ${ }^{*} \mathbf{p}<\mathbf{0 . 0 5}$ significantly different from the training rest group.

of GSH in the sample. In this assay, both GSH and oxidized glutathione are measured and the assay reflects total glutathione levels. Heart levels of 8-OHdG were determined using a commercially available kit from the Cayman Chemical (Cat. \#589320, Cayman Chemical Co., Ann Arbor, MI, USA) according to the manufacturer's instructions. Heart SOD activity was determined using a commercialized chemical SOD assay kit (Cat. \#706002, Cayman Chemical Co., Ann Arbor, MI, USA). The kit utilizes a tetrazolium salt for the detection of superoxide radicals generated by xanthine oxidase and hypoxanthine. The reactions were initiated by adding xanthine oxidase, by incubating $20 \mathrm{~min}$ at room temperature, and then by reading the absorbance at $450 \mathrm{~nm}$. One unit of SOD activ-

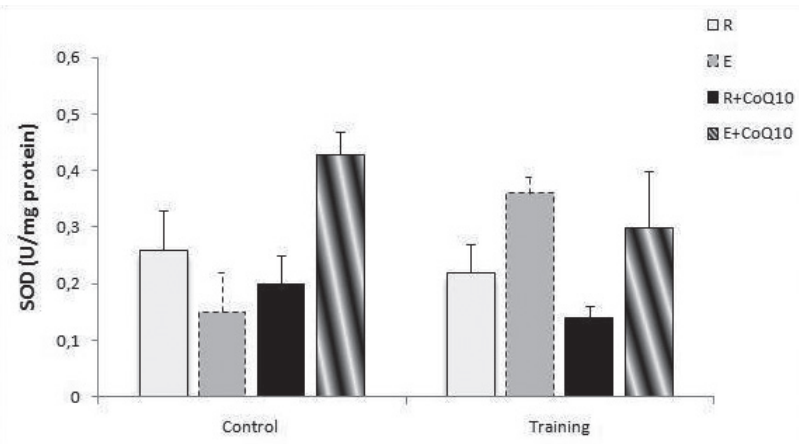

Fig. 3. The effects of swimming training, $\mathrm{CoQ}_{10}$ supplementation and acute exhaustive exercise on superoxide dismutase (SOD) in the rat heart. The data are presented as means \pm SEM. There was a significant effect of acute exhaustive exercise on the SOD level in heart tissue (F $=5.71, \mathbf{p}<0.05) . R=$ Rest group, $\mathbf{E}=$ Exhausted group, $R+C_{0} Q_{10}=$ Rest group with $\mathrm{CoQ}_{10}$ supplement, $\mathrm{E}+\mathrm{Co}_{10}=$ Exhausted group with $\mathrm{CoQ}_{10}$ supplement.

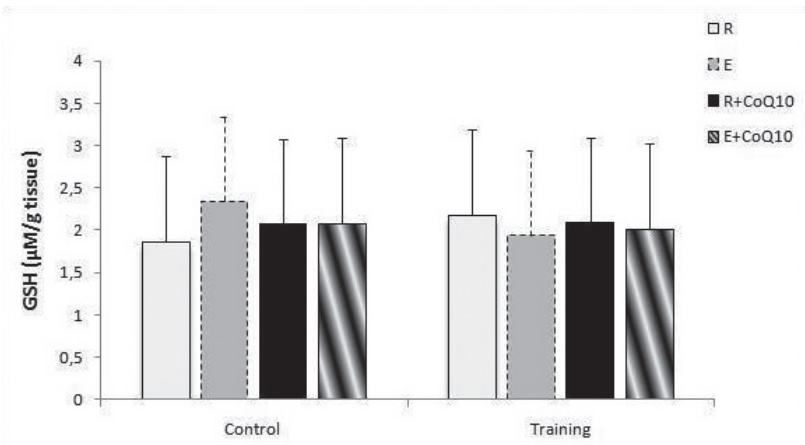

Fig. 4. The effects of swimming training, $\mathrm{CoQ}_{10}$ supplementation and acute exhaustive exercise on total glutathione (GSH) in the rat heart. The data are presented as means \pm SEM. There was a significant interaction effect of acute exhaustive exercise and training on the GSH level in heart tissue $(\mathrm{F}=6.66, \mathrm{p}<\mathbf{0 . 0 5}) . \mathrm{R}=$ Rest group, $\mathrm{E}=$ Exhausted group, $\mathrm{R}+\mathrm{CoQ}_{10}=$ Rest group with $\mathrm{CoQ}_{10}$ supplement, $\mathrm{E}+\mathrm{CoQ}_{10}=\mathrm{Ex}$ hausted group with $\mathrm{CoQ}_{10}$ supplement.

ity was defined as the amount of enzyme needed to inhibit 50\% dismutation of the superoxide radical. Protein content of the tissues was determined by the method of Lowry et al (31).

\section{Statistical analysis}

Statistical analyses were performed using SPSS version 15.0. Statistical significance was set at a level of $\mathrm{p}<0.05$, and data were expressed as the mean \pm SEMA three-way ANOVA was performed to examine the main effects of $\mathrm{CoQ}_{10}$ supplement, swimming training, and acute exhaustive exercise $(2 \times 2 \times 2)$ as well as any possible interactions between these variables. One-way ANOVA with Bonferroni post-hoc test was used to compare group means.

\section{Results}

Table 1 shows the effects of $\mathrm{CoQ}_{10}$, training and acute exhaustive exercise on levels of MDA, 8-OHdG, GSH and activity of SOD in the heart tissue. 
The swimming time to exhaustion was significantly longer in the trained-exhausted $(2: 36 \pm 0: 34 \mathrm{~h})$ and trained-exhausted with $\mathrm{CoQ}_{10}(2: 56 \pm 0: 16 \mathrm{~h})$ groups than the control-exhausted with $\mathrm{CoQ}_{10}(1: 03 \pm 0: 01 \mathrm{~h})(\mathrm{p}<0.05)$. The time to exhaustion in controlexhausted group $(2: 11 \pm 0: 13 \mathrm{~h})$ was not significantly different from other groups.

Training and exhaustive exercise interaction effects were significant on MDA levels $(F=23.10, p<0.05)$. MDA levels after exhaustion were lower compared to the respective rest group only in the training group. However, in the control group, MDA levels were significantly higher $(\mathrm{p}<0.05)$. A significant interaction between $\mathrm{CoQ}_{10}$ supplementation, training and exhaustive exercise on MDA levels was observed $(F=19.29, p<0.05)$. In the control group, MDA levels were higher in the rest with $\mathrm{CoQ}_{10}$ supplement group compared to the rest group $(\mathrm{p}<0.05)$. In the training group, MDA levels of rest group and rest with $\mathrm{CoQ}_{10}$ supplement group were higher than those of the control rest group $(\mathrm{p}<0.05)$ (Fig. 1).

Figure 2 shows that there was a significant main effect of exhaustive exercise on levels of $8-\mathrm{OHdG}$ in rat heart $(\mathrm{F}=4.38$, $\mathrm{p}<0.05$ ). Exhaustive exercise increased $8-\mathrm{OHdG}$ levels in all groups except training group. There was also a significant interaction effect between $\mathrm{CoQ}_{10}$ and training $(\mathrm{F}=4.63, \mathrm{p}<0.05)$. 8-OHdG levels of trained rest group were higher than those of the control rest and trained-rest with $\mathrm{CoQ}_{10}$ supplement groups $(\mathrm{p}<0.05)$.

Figure 3 shows that the effect of exhaustive exercise was significant on SOD activity $(\mathrm{F}=5.71, \mathrm{p}<0.05)$. The exhaustive exercise decreased SOD activity in control-exhausted group, while increased in other exhausted groups. However, post hoc analysis did not detect significant differences between the groups $(\mathrm{p}>0.05)$.

Figure 4 shows that swimming training and exhaustive exercise interaction effects were significant on GSH levels ( $\mathrm{F}=6.66$, $\mathrm{p}<0.05)$. Three-way ANOVA test demonstrated that GSH levels were increased in control-rest group, but decreased in training rest group by exhaustive exercise. However, these increases or decreases were not statistically significant $(\mathrm{p}>0.05)$.

\section{Discussion}

Heart is a unique muscle that works continuously, unlike skeletal muscles. Thus heart may always be exposed to some degree of oxidative stress (32). However, tissues with high oxygen consumption rates, such as liver, heart, and brain, constitutively express higher levels of antioxidant enzymes than those characterized by low oxygen consumption (33). In this study, the effects of training and $\mathrm{CoQ}_{10}$ supplementation on the acute exhaustive exerciseinduced oxidative stress markers were investigated in rat heart. One of the most important findings of this study was that training alone or in combination with $\mathrm{CoQ}_{10}$ supplementation reduced to increasing heart MDA levels due to exhaustive exercise. Besides, a significant interaction effect between $\mathrm{CoQ}_{10}$ supplementation and training on 8-OHdG levels was found. GSH levels and SOD activity also showed quite different responses to exhaustive exercise or swimming training in rat heart. However, they were not affected by $\mathrm{CoQ}_{10}$ supplementation.
Acute exercise increases MDA levels $(34,35)$ whereas chronic exercise reduces MDA levels in the heart (36-38). However, some investigators indicate that heart MDA level was not affected by either acute or chronic exercise (39-41). In this study, MDA levels at rest were higher in the training group compared to the control group. It might be suggested that regular physical training may produce oxidative stress, which may lead to generation of free radicals and lipid peroxidation (42). Also, this may be associated with differences in swimming time to exhaustion among the groups. The trained groups had longer time to exhaustion than the untrained groups. Several studies investigated the role of $\mathrm{CoQ}_{10}$ supplementation on exercise-induced lipid peroxidation $(43,44)$. We found that training reduced MDA levels, also training in combination with $\mathrm{CoQ}_{10}$ supplementation prevented to increase MDA levels induced by exhaustive exercise in rat heart. In parallel with these results, Faff and Frankiewicz-Jóźko (43) found that $\mathrm{CoQ}_{10}$ substantially suppressed the exhaustive exercise-induced increase in the heart, liver, and gastrocnemius muscle MDA levels. In addition, Kon et al (44) indicated that $\mathrm{CoQ}_{10}$ supplementation reduced exhaustive exercise-induced muscular injury. On the other hand, in studies in humans, Laaksonen et al. (45) reported that neither $\mathrm{CoQ}_{10}$ supplementation nor exercise affected serum MDA levels in trained young and older men. In another study, serum MDA levels were also unaffected by treatment of $\mathrm{CoQ}_{10}$ in trained cyclists (46). On the contrary, Cooke et al (47) stated that acute supplementation with $\mathrm{CoQ}_{10}$ resulted in higher MDA levels during and following exercise. They indicated that acute and chronic supplementation of $\mathrm{CoQ}_{10}$ may affect acute and/or chronic responses to various types of exercise. These disparate results may be due to differences in dose and duration of $\mathrm{CoQ}_{10}$ treatment and/or the training status of participants. Also, the type of exercise may influence the lipid peroxidation in tissues differently. In this study, swimming was selected because muscle trauma caused by prolonged running, exercise-stimulated electric shock, and plyometric contractions could induce oxidative stress (48). For instance, Nakao et al (32) showed that compared with running, swimming leads to a wide difference of physical responses and mechanical stresses because of effects of water pressure, utilization of different muscles, and reduced effects of gravity. Besides, oxidative stress by acute or chronic exercise elicits different responses depending on the organ tissue type and its endogenous antioxidant levels. The differences among organs may be dependent on several factors, such as oxygen consumption, susceptibility to oxidants and to antioxidant enzyme activation, antioxidant levels, and other repair systems (36).

In addition to lipid peroxidation, ROS are known to cause oxidative modifications of protein and DNA damage (49). Oxidative stress-induced DNA damage and insufficient DNA repair may play an important role in the etiology of cancer, diabetes and arteriosclerosis (50). However, there is one small study regarding the effect of exercise on DNA damage. In this study, exhaustive exercise increased 8-OHdG levels in control groups. Also, we demonstrated that there was a significant interaction between $\mathrm{CoQ}_{10}$ supplementation and training on DNA damage showing that $\mathrm{CR}+\mathrm{CoQ}_{10}$ group had higher $8-\mathrm{OHdG}$ levels than 
$\mathrm{TR}+\mathrm{CoQ}_{10}$ group. Asami et al (51) found that the 8-OHdG levels in the forced exercise rats were significantly elevated as compared with those in the spontaneously exercised rats in heart and other tissues and they indicate that the intensity of exercise training is an important determinant of oxidative DNA damage. Conversely, other investigators reported that DNA damage in heart tissue was unaffected by either acute or chronic exercise $(36,52)$. However, Ramirez-Tortosa et al (53) stated that $\mathrm{CoQ}_{10}$ supplementation decreased DNA damage in peripheral blood lymphocytes. These controversial findings may be explained by differences in training intensity, duration and type of training and/or training status (54). Also, the generation of oxidative stress in DNA and lipids is different after exercise training. This is possibly due to different mechanisms or different activities of specific antioxidant and repair systems (48).

SOD is the major defence upon superoxide radicals and is the first defence line against oxidative stress. (49). In the present study, heart SOD activity in the control group (not receiving the training or supplementation) was decreased by exhaustive exercise, but increased in the $\mathrm{CoQ}_{10}$ groups compared to their controls. Swimming training and/or $\mathrm{CoQ}_{10}$ supplementation lead to reduced levels of MDA, and enhanced SOD activity at exhaustion. Similarly, Nishiyama et al. (55) claim that the elevated MDA level by exercise may relate to a decrease in SOD activity during exercise. Another study reported that acute supplementation with $\mathrm{CoQ}_{10}$ resulted in lower serum SOD activity during and following exercise (47). In addition, Gül et al (41) found that heart SOD activity was decreased by acute exercise in untrained rats; however, this decrease was not observed in trained rats. These results suggest that SOD activity was reduced in order to prevent lipid peroxidation in the heart. On the other hand, increased SOD levels in other groups may indicate a possible beneficial effect of chronic exercise. Conversely, Qiao et al (56) reported that intermittent anaerobic swimming resulted in higher SOD activity in both muscle and heart in untrained rats. Atalay et al (57) examined the effect of sprint training on rat skeletal muscle and heart antioxidant defences. They found that SOD activity remained unchanged in skeletal muscle and heart. Similarly, Tiidus and Houston (58) indicated that endurance training did not change SOD activity in skeletal muscles, heart, or liver of female rats. However, Gündüz et al (40) reported that one year's swimming exercise elevated SOD activity in several tissues including heart. Furthermore, Husain and Somani (59) stated that SOD activity in heart tissue was increased by exercise training ( 6.5 weeks). The results of another study showed that high-intensity exercise $\geq 30$ $\mathrm{min} /$ day) or moderate-intensity exercise of long duration $\geq 60 \mathrm{~min} /$ day) is effective in upregulating SOD activity in the rat ventricular myocardium (60). The SOD levels seemed to be regulated by translational and/or posttranslational mechanisms during exercise training, though the mechanisms remain to be clarified. In addition, whether or not increases in SOD levels actually reduce exerciseinduced oxidative stress also remains vague (32).

GSH serves as a sensitive marker of oxidative stress and it plays an important role in maintaining the integrity of the cell system (61). In this study, exhaustive exercise increased GSH levels in only the control group (not receiving the training or supplementation), although it reduced GSH levels in the training group. It is hypothesized that exercise increases the blood flow in the cardiac muscle, which in turn increases the delivery of GSH to this organ. This enhanced intracellular transport of GSH seems to be essential in maintaining the redox state and to cope with the oxidative stress during exercise training. Another possible mechanism for the increase in GSH during exercise training could be hormonal effects. Exercise training triggers a hormonal response that can influence the efflux of GSH from liver to blood (62). Rigorous swim training reduces heart mitochondrial function, making them more susceptible to oxidative stress, and that this damaging effect may be related to a diminished GSH reserve (63), whereas chronic moderate exercise can lead to protective intrinsic adaptations in the myocardium that specifically attenuate myocardial injury and enhance coronary flow when challenged with $\mathrm{H}_{2} \mathrm{O}_{2}$ (64). In another study, Liu et al (36) reported that chronic exercise (8-wk treadmill running) and acute exercise (treadmill running to exhaustion) increased GSH in the heart tissue of rats. However, the increment induced by chronic exercise in GSH was not significant. Conversely, Husain and Hazelrigg (37) indicated that training for 8 weeks significantly enhanced cardiac GSH levels in rats. Similarly, Husain and Somani (59) showed that GSH activities in heart tissue were significantly increased by treadmill exercise training for 6.5 weeks. Furthermore, some researchers reported a significant increase in GSH after training exercise (10 weeks) but not after acute exercise $\left(100 \% \mathrm{VO}_{2 \max }\right)$ in rat heart (62). However, Venditti et al (65) found that heart antioxidant capacity remained unchanged after prolonged exercise (210 min), while it underwent a decrease after exhausting swimming. It might be suggested that GSH is actively used in the myocardium during prolonged exercise at moderate intensity and that GSH deficiency is tolerated by the heart, possibly compensated for by an increased GSH uptake from the plasma (66). Another study reported that heart tissue has four times less antioxidant enzyme activity and GSH levels compared to liver and other tissues. Therefore, heart tissue may be more vulnerable to peroxidative damage due to oxidative stress (59).

The levels of GSH in heart were not affected by $\mathrm{CoQ}_{10}$ supplementation in the present study. However, El-Abhar (67) found that GSH levels were restored, while glutathione peroxidase levels were elevated above normal by the administration of $\mathrm{CoQ}_{10}$ in gastric mucosa of rats. Moreover, González et al. (68) indicated that the co-administration of $\mathrm{CoQ}_{10}$ recovered mitochondrial oxidized/ reduced GSH ratio, and reduced ROS generation. Another study report showed that supplementation with $\mathrm{CoQ}_{10}$ led to increased erythrocyte GSH concentration in diabetic rats (25). Nevertheless, Nasuti et al (69) stated that supplementation with Vitamin $\mathrm{E}+\mathrm{CoQ}_{10}$ could not prevent the reduction in GSH in adolescent rats. This effect could be related to the dual activity of $\mathrm{CoQ}_{10}$ that can act as antioxidant but also as pro-oxidant.

The results of the present study show that $\mathrm{CoQ}_{10}$ supplementation and swimming training have interactive effects on lipid peroxidation and DNA damage in the heart tissue. Also, $\mathrm{CoQ}_{10}$ supplementation alone did not affect antioxidant status. 


\section{References}

1. Melzer K, Kayser B, Pichard C. Physical activity: the health benefits outweigh the risks. Curr Opin Clin Nutr Metab Care 2004; 7 (6): 641-647.

2. Alessio HM. Exercise-induced oxidative stress. Med Sci Sports Exerc 1993; 25 (2): 218-224.

3. Radak Z, Taylor AW, Ohno H, Goto S. Adaptation to exercise-induced oxidative stress: from muscle to brain. Exerc Immunol Rev 2001; 7: 90-107.

4. Atalay M, Sen CK. Physical exercise and antioxidant defenses in the heart. Ann N Y Acad Sci 1999; 874: 169-177.

5. Gutteridge JM. Lipid peroxidation and antioxidants as biomarkers of tissue damage. Clin Chem 1995; 41 (12 Pt 2): 1819-1828.

6. Urso ML, Clarkson PM. Oxidative stress, exercise and antioxidant supplementation. Toxicology 2003; 189: 41-54.

7. Jackson MJ, Papa S, Bolaños J, Bruckdorfer R, Carlsen H, Elliott RM et al. Antioxidants, reactive oxygen and nitrogen species, gene induction and mitochondrial function. Mol Aspects Med 2002; 23 (1-3): 209-285.

8. Valko M, Leibfritz D, Moncol J, Cronin MT, Mazur M, Telser J. Free radicals and antioxidants in normal physiological functions and human disease. Int J Biochem Cell Biol 2007; 39 (1): 44-84.

9. Valko M, Rhodes CJ, Moncol J, Izakovic M, Mazur M. Free radicals, metals and antioxidants in oxidative stress-induced cancer. Chem Biol Interact 2006; 160 (1): 1-40.

10. Powers SK, DeRuisseau KC, Quindry J, Hamilton KL. Dietary antioxidants and exercise. J Sports Sci 2004; 22 (1): 81-94.

11. Quinzii CM, DiMauro S, Hirano M. Human coenzyme Q10 deficiency. Neurochem Res 2007; 32 (4-5): 723-7.

12. Ross SM. Coenzyme q10: ubiquinone: a potent antioxidant and key energy facilitator for the heart. Holist Nurs Pract 2007; 21 (4): 213-214.

13. Turunen M, Olsson J, Dallner G. Metabolism and function of coenzyme Q. Biochim Biophys Acta 2004; 1660 (1-2): 171-199.

14. Bhagavan HN, Chopra RK. Coenzyme Q10: absorption, tissue uptake, metabolism and pharmacokinetics. Free Radic Res 2006; 40 (5): 445-453.

15. Crane FL. New functions for coenzyme Q. Protoplasma 2000; 213: 127-133.

16. Frei B, Kim MC, Ames BN. Ubiquinol-10 is an effective lipid-soluble antioxidant at physiological concentrations. Proc Natl Acad Sci USA 1990; 87 (12): 4879-4883.

17. Crane FL. Biochemical functions of coenzyme Q10. J Am Coll Nutr 2001; 20 (6): 591-598.

18. Groneberg DA, Kindermann B, Althammer M, Klapper M, Vormann J, Littarru GP et al. Coenzyme Q10 affects expression of genes involved in cell signalling, metabolism and transport in human CaCo-2 cells. Int J Biochem Cell Biol 2005; 37 (6): 1208-1218.

19. Fu X, Ji R, Dam J. Antifatigue effect of coenzyme Q10 in mice. J Med Food 2010; 13 (1): 211-215.

20. Gökbel H, Gül I, Belviranl M, Okudan N. The effects of coenzyme Q10 supplementation on performance during repeated bouts of supramaximal exercise in sedentary men. J Strength Cond Res 2010; 24 (1): 97-102.
21. Mizuno K, Tanaka M, Nozaki S, Mizuma H, Ataka S, Tahara T et al. Antifatigue effects of coenzyme Q10 during physical fatigue. Nutrition 2008; 24 (4): 293-299.

22. Munkholm H, Hansen HH, Rasmussen K. Coenzyme Q10 treatment in serious heart failure. Biofactors 1999; 9 (2-4): 285-289.

23. Witting PK, Pettersson K, Letters J, Stocker R. Anti-atherogenic effect of coenzyme Q10 in apolipoprotein E gene knockout mice. Free Radic Biol Med 2000; 29 (3-4): 295-305.

24. Dhanasekaran M, Ren J. The emerging role of coenzyme Q-10 in aging, neurodegeneration, cardiovascular disease, cancer and diabetes mellitus. Curr Neurovasc Res 2005; 2 (5): 447-459.

25. Al-Thakafy HS, Khoja SM, Al-Marzouki ZM, Zailaie MZ, AlMarzouki KM. Alterations of erythrocyte free radical defense system, heart tissue lipid peroxidation, and lipid concentration in streptozotocininduced diabetic rats under coenzyme Q10 supplementation. Saudi Med J 2004; 25 (12): 1824-1830.

26. Rosenfeldt FL, Haas SJ, Krum H, Hadj A, Ng K, Leong JY, et al. Coenzyme Q10 in the treatment of hypertension: a meta-analysis of the clinical trials. J Hum Hypertens 2007; 21 (4): 297-306.

27. Beal MF. Coenzyme Q 10 as a Possible Treatment for Neurodegenerative Diseases. Free Radical Research 2002; 36 (4): 455-460.

28. Somayajulu M, McCarthy S, Hung M, Sikorska M, BorowyBorowski $\mathbf{H}$ et al. Role of mitochondria in neuronal cell death induced by oxidative stress; neuroprotection by Coenzyme Q10. Neurobiol Dis 2005; 18 (3): 618-627.

29. Kwon DK, Hwang KH, Kim YK, Lee KH, Song YJ. Effects of swimming exercise and soybean supplementation on the immune functions of rats fed a high-fat diet. Clin Exp Pharmacol Physiol 2008; 35 (5-6): 638-642.

30. Gonchar O. Muscle fiber specific antioxidative system adaptation to swim training in rats: influence of intermittent hypoxia. J Sports Sci Med 2005; 4: 160-169.

31. Lowry OH, Rosebrough NJ, Farr AL, Randall RJ. Protein measurement with the Folin phenol reagent. J Biol Chem 1951; 193 (1): 265-275.

32. Nakao C, Ookawara T, Kizaki T, Oh-Ishi S, Miyazaki H, Haga S et al. Effects of swimming training on three superoxide dismutase isoenzymes in mouse tissues. J Appl Physiol 2000; 88 (2): 649-654.

33. Jenkins RR. Exercise, oxidative stress, and antioxidants: a review. Int J Sport Nutr 1993; 3 (4): 356-375.

34. Frankiewicz-JóźkoA, FaffJ,Sieradzan-Gabelska B. Changes in concentrations of tissue free radical marker and serum creatine kinase during the postexercise period in rats. EurJ Appl Physiol Occup Physiol 1996; 74 (5): 470-474.

35. Venditti P, Di Meo S. Antioxidants, tissue damage, and endurance in trained and untrained young male rats. Arch Biochem Biophys 1996; 331 (1): 63-68.

36. Liu J, Yeo HC, Overvik-Douki E, Hagen T, Doniger SJ, Chyu DW et al. Chronically and acutely exercised rats: biomarkers of oxidative stress and endogenous antioxidants. J Appl Physiol 2000; 89 (1): 21-28.

37. Husain K, Hazelrigg SR. Oxidative injury due to chronic nitric oxide synthase inhibition in rat: effect of regular exercise on the heart. Biochim Biophys Acta 2002; 1587 (1): 75-82.

38. Teixeira A, Müller L, dos Santos AA, Reckziegel P, Emanuelli T, Rocha JB, et al. Beneficial effects of gradual intense exercise in tissues of rats fed with a diet deficient in vitamins and minerals: a pilot study. Nutrition 2009; 25 (5): 590-596. 
39. Benderitter M, Hadj-Saad F, Lhuissier M, Maupoil V, Guilland JC, Rochette L. Effects of exhaustive exercise and vitamin B6 deficiency on free radical oxidative process in male trained rats. Free Radic Biol Med 1996; 21 (4): 541-549.

40. Gündüz F, Sentürk UK, Kuru O, Aktekin B, Aktekin MR. The effect of one year's swimming exercise on oxidant stress and antioxidant capacity in aged rats. Physiol Res 2004; 53 (2): 171-176.

41. Gül M, Demircan B, Taysi S, Oztasan N, Gumustekin K, Siktar E et al. Effects of endurance training and acute exhaustive exercise on antioxidant defense mechanisms in rat heart. Comp Biochem Physiol A Mol Integr Physiol 2006; 143 (2): 239-245.

42. Lekhi C, Gupta PH, Singh B. Influence of exercise on oxidant stress products in elite Indian cyclists. Br J Sports Med 2007; 41 (10): 691-693.

43. Faff J, Frankiewicz-Jóźko A. Effect of ubiquinone on exercise-induced lipid peroxidation in rat tissues. Eur J Appl Physiol Occup Physiol 1997; 75 (5): 413-417.

44. Kon M, Kimura F, Akimoto T, Tanabe K, Murase Y, Ikemune $S$ et al. Effect of Coenzyme Q10 supplementation on exercise-induced muscular injury of rats. Exerc Immunol Rev 2007; 13: 76-88.

45. Laaksonen R, Fogelholm M, Himberg JJ, Laakso J, Salorinne Y. Ubiquinone supplementation and exercise capacity in trained young and older men. Eur J Appl Physiol Occup Physiol 1995; 72 (1-2): 95-100.

46. Braun B, Clarkson PM, Freedson PS, Kohl RL. Effects of coenzyme Q10 supplementation on exercise performance, VO2max, and lipid peroxidation in trained cyclists. Int J Sport Nutr 1991; 1 (4): 353-365.

47. Cooke M, Iosia M, Buford T, Shelmadine B, Hudson G, Kerksick C et al. Effects of acute and 14-day coenzyme Q10 supplementation on exercise performance in both trained and untrained individuals. J Int Soc Sports Nutr 2008; 5: 8 .

48. Radak Z, Kaneko T, Tahara S, Nakamoto H, Ohno H, Sasvári M et al. The effect of exercise training on oxidative damage of lipids, proteins, and DNA in rat skeletal muscle: evidence for beneficial outcomes. Free Radic Biol Med 1999; 27 (1-2): 69-74.

49. Finaud J, Lac G, Filaire E. Oxidative stress relationship with exercise and training. Sports Med 2006; 36: 327-358.

50. Wu LL, Chiou CC, Chang PY, Wu JT. Urinary 8-OHdG: a marker of oxidative stress to DNA and a risk factor for cancer, atherosclerosis and diabetics. Clin Chim Acta 2004; 339 (1-2): 1-9.

51. Asami S, Hirano T, Yamaguchi R, Tsurudome Y, Itoh H, Kasai H. Effects of forced and spontaneous exercise on 8-hydroxydeoxyguanosine levels in rat organs.Biochem Biophys Res Commun 1998;243 (3): 678-682.

52. Pozzi R, Rosa JC, Eguchi R, Oller do Nascimento CM, Oyama LM, Aguiar O Jr et al. Genetic damage in multiple organs of acutely exercised rats. Cell Biochem Funct 2010; 28 (8): 632-636.

53. Ramirez-Tortosa MC, Granados S, Ramirez-Tortosa CL, Ochoa JJ, Camacho P, García- Valdés L et al. Oxidative stress status in liver mitochondria and lymphocyte DNA damage of atherosclerotic rabbits supplemented with water soluble coenzyme Q10. Biofactors 2008; 32 (1-4): 263-273.

54. Reichhold S, Neubauer O, Bulmer AC, Knasmüller S, Wagner KH. Endurance exercise and DNA stability: is there a link to duration and intensity? Mutat Res 2009; 682 (1): 28-38.
55. Nishiyama Y, Ikeda H, Haramaki N, Yoshida N, Imaizumi T. Oxidative stress is related to exercise intolerance in patients with heart failure. Am Heart J. 1998 Jan;135(1):115-20.

56. Qiao D, Hou L, Liu X. Influence of intermittent anaerobic exercise on mouse physical endurance and antioxidant components. Br J Sports Med 2006; 40 (3): 214-218.

57. Atalay M, Seene T, Hänninen O, Sen CK. Skeletal muscle and heart antioxidant defences in response to sprint training. Acta Physiol Scand 1996; 158 (2): 129-134.

58. Tiidus PM, Houston ME. Antioxidant and oxidative enzyme adaptations to vitamin E deprivation and training. Med Sci Sports Exerc 1994; 26 (3): 354-359.

59. Husain K, Somani SM. Response of cardiac antioxidant system to alcohol and exercise training in the rat. Alcohol 1997; 14 (3): 301-307.

60. Powers SK, Criswell D, Lawler J, Martin D, Lieu FK, Ji LL et al. Rigorous exercise training increases superoxide dismutase activity in ventricular myocardium. Am J Physiol 1993; 265 (6 Pt 2): H2094-8.

61. Kakarla P, Vadluri G, Reddy KS, Leeuwenburgh C. Vulnerability of the mid aged rat myocardium to the age-induced oxidative stress: influence of exercise training on antioxidant defense system. Free Radic Res 2005; 39 (11): 1211-1217.

62. Somani SM, Frank S, Rybak LP. Responses of antioxidant system to acute and trained exercise in rat heart subcellular fractions. Pharmacol Biochem Behav 1995; 51 (4): 627-634.

63. Leichtweis SB, Leeuwenburgh C, Parmelee DJ, Fiebig R, Ji LL. Rigorous swim training impairs mitochondrial function in post-ischaemic rat heart. Acta Physiol Scand 1997; 160 (2): 139-148.

64. Taylor RP, Ciccolo JT, Starnes JW. Effect of exercise training on the ability of the rat heart to tolerate hydrogen peroxide. Cardiovasc Res 2003; 58 (3): 575-581.

65. Venditti P, Piro MC, Artiaco G, Di Meo S. Effect of exercise on tissue anti-oxidant capacity and heart electrical properties in male and female rats. Eur J Appl Physiol Occup Physiol 1996; 74 (4): 322-329.

66. Leeuwenburgh C, Leichtweis S, Hollander J, Fiebig R, Gore M, Ji LL. Effect of acute exercise on glutathione deficient heart. Mol Cell Biochem 1996; 156 (1): 17-24.

67. El-Abhar HS. Coenzyme Q10: a novel gastroprotective effect via modulation of vascular permeability, prostaglandin $E_{2}$, nitric oxide and redox status in indomethacin-induced gastric ulcer model. Eur J Pharmacol 2010; 649 (1-3): 314-319.

68. González R, Ferrín G, Hidalgo AB, Ranchal I, López-Cillero P, Santos-Gónzalez M et al. N-acetylcysteine, coenzyme Q10 and superoxide dismutase mimetic prevent mitochondrial cell dysfunction and cell death induced by d-galactosamine in primary culture of human hepatocytes. Chem Biol Interact 2009; 181 (1): 95-106.

69. Nasuti C, Falcioni ML, Nwankwo IE, Cantalamessa F, Gabbianelli R. Effect of permethrin plus antioxidants on locomotor activity and striatum in adolescent rats. Toxicology 2008; 251 (1-3): 45-50.

Received October 7, 2011. Accepted January 17, 2012. 